\title{
Coastal eutrophication assessment in the United States
}

\author{
DONALD SCAVIA $^{1, *}$ and SUZANNE B. BRICKER ${ }^{2}$ \\ ${ }^{1}$ University of Michigan, Ann Arbor, MI, USA; ${ }^{2}$ National Oceanic and Atmospheric Administration, \\ Silver Spring, MD, USA; *Author for correspondence (e-mail: scavia@umich.edu; phone: \\ +1-734-615-4860; fax: +1-734-763-8965)
}

Key words: Assessment, Coastal, Eutrophication, Gulf of Mexico, Hypoxia

\begin{abstract}
Recent national assessments document that nitrogen-driven coastal eutrophication is widespread and increasing in the United States. This significant coastal pollution problem includes impacts including increased areas and severity of hypoxic and anoxic waters; alteration of food webs; degradation and loss of sea grass beds, kelp beds and coral reefs; loss of biodiversity; and increased incidences and duration of harmful algal blooms. In this paper, we review two complementary approaches to assessing the causes and consequences of these trends, as well as potential remedies for them. The first is a national-scale assessment, drawn primarily from expert knowledge of those most familiar with the individual estuaries and integrated into a common analysis framework. The second approach, focused on the Mississippi/Atchafalaya basin - the largest US drainage basin - draws upon both quantitative and qualitative analyses within a comprehensive framework, Integrated Assessment.
\end{abstract}

Recent national assessments (e.g., Bricker et al. 1999; NRC 2000; CENR 2003) document that coastal eutrophication is widespread and increasing in the United States and that, among the diverse issues confronting US coastal systems, the impact of excess nutrients is the most important pollution problem (Howarth et al. 2000; NRC 2000; Ocean Commission 2004). These impacts include increased areas and severity of hypoxic and anoxic waters; alteration of food webs; degradation and loss of sea grass beds, kelp beds and coral reefs; loss of biodiversity; and increased incidences and duration of harmful algal blooms. While both nitrogen and phosphorus contribute to nutrient pollution, nitrogen is the more significant driver of eutrophication in most US coastal areas and humans have increased the average flux of nitrogen to the coastal waters of the United States by four to fivefold; in some regions the increase has been as large as 10-fold (NRC 2000; Howarth et al. 2002). Population growth, expanded land development, and intensified agriculture are likely to increase nitrogen loads substantially in the future.

Efforts to address these issues most often require actions at local levels; however, there is value in providing both national and watershed perspectives on the issue. In this paper, we review two complementary approaches to assessment. The first is a national assessment, drawn primarily from expert knowledge of those most familiar with the individual estuaries and integrated 
into a common analysis framework. The second approach - an Integrated Assessment of the Causes and Consequences of Hypoxia in the Northern Gulf of Mexico - addresses the largest US drainage basin and draws upon both quantitative and qualitative analyses within a comprehensive framework that considers causes and consequences of nutrient inputs, and examines alternatives to reduce, mitigate and control nutrient related impacts. The sections below outline both approaches and illustrate how they produce information at complementary scales and for different audiences.

\section{National estuarine eutrophication assessment}

In the early 1990s in response to the knowledge that some estuaries were showing signs of nutrient related degradation as evidenced by hypoxia in Long Island Sound, Chesapeake and Mobile bays (Welsh 1991) and the concern that this might be a wide spread problem, NOAA conducted a nationwide assessment to discern the magnitude, severity, and location of eutrophic conditions. The intent was to learn whether these problems were local, regional, or national in scale, to determine probable causes, and to provide this information to managers such that observed problems could be addressed at the appropriate level.

The National Estuarine Eutrophication Assessment (NEEA) was carried out in three phases. First, questionnaires were used nationally to collect data and information for 16 nutrient related water quality variables (NOAA 1996, 1997a-c, 1998). Second, results for six of the 16 variables were selected to provide an assessment of overall conditions within the water bodies (Bricker et al. 1999). Finally, additional databases were used to evaluate the probable causes of observed conditions and to make projections about future outlook.

The original method is described here in brief, as are recent improvements and modifications made by the Assessment of Estuarine Trophic Status group (ASSETS, Bricker et al. 2003). A full description of the original method can be found in Bricker et al. (1999) and details for modifications can be found in Bricker et al. (2003). Additionally, a brief description is provided of the continuation of this work through the NEEA Update Program (Bricker et al. 2004). This program is intended to provide results to inform managers, researchers, and politicians about the success of legislation and management measures designed to address eutrophication issues. The update, anticipated for release in late 2006, (http://ian.umces.edu/neea), will provide case studies that examine the success of management since the early 1990s in order to inform recommendations for analysis and application of appropriate management measures in systems nationwide. It is meant to be a companion program to a National Research Program for Nutrient Pollution in Coastal Waters (Howarth et al. 2003) and interactive with European Commission efforts such as the Water Framework Directive 2000/60/EC (WFD e.g. OSPAR 2002, 2003; Coast 2003). 


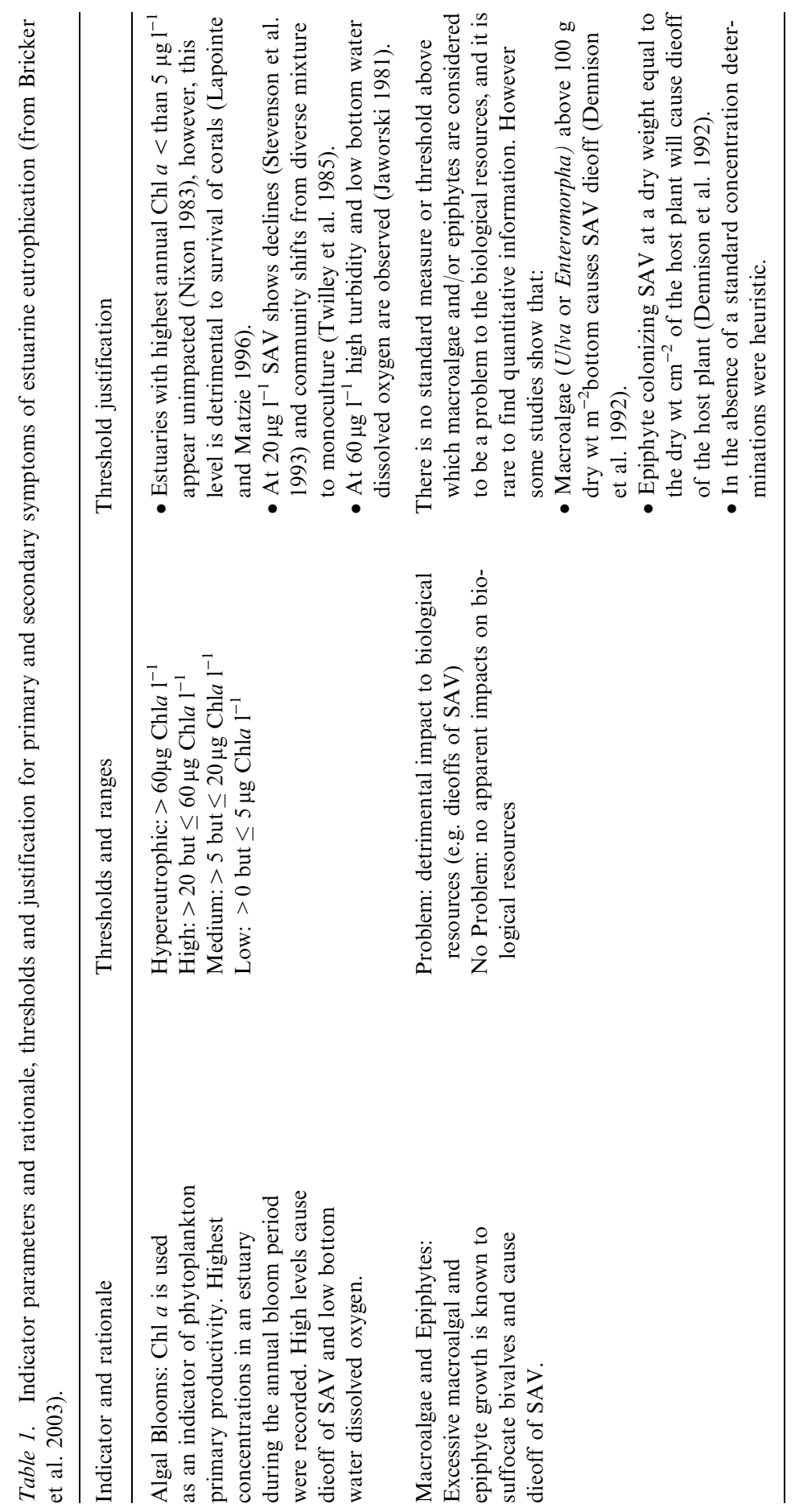




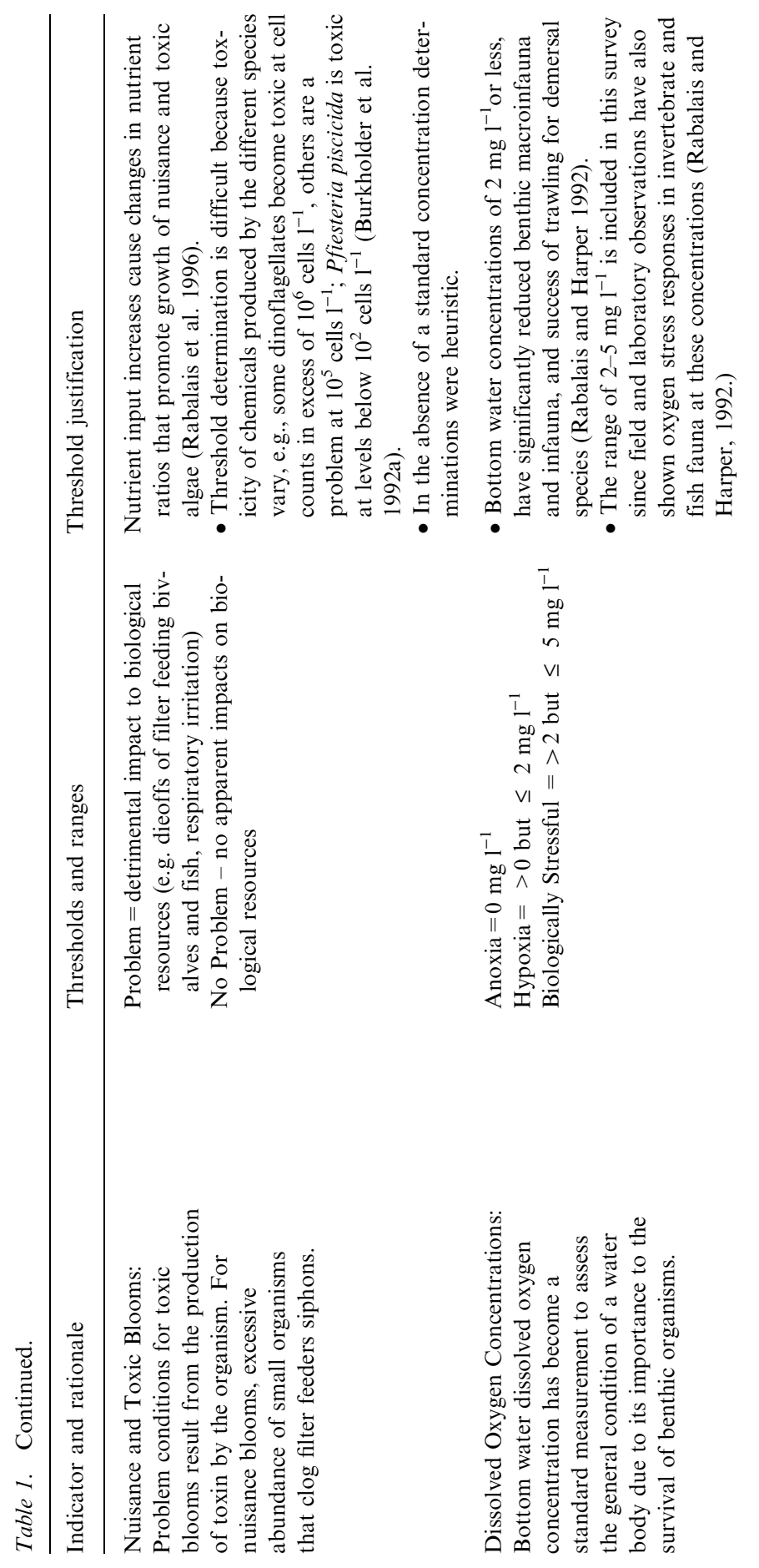



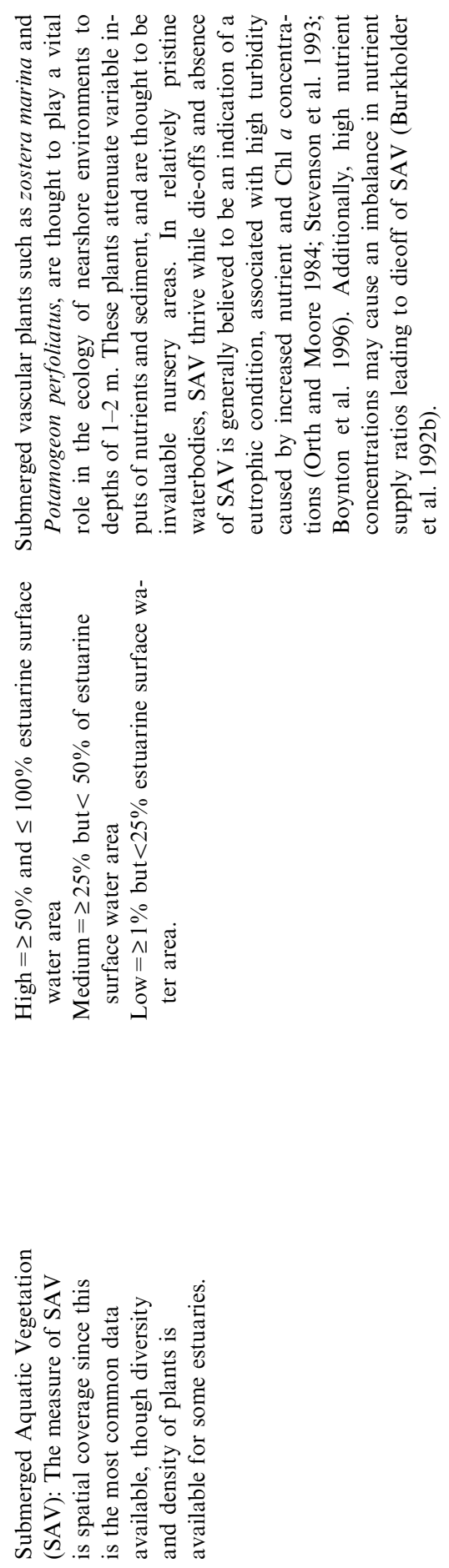


\section{Indicator selection and characterization}

Sixteen nutrient-related water quality indicators were selected to characterize eutrophic conditions across very different systems (Hinga et al. 1991). This suite of variables was broad enough to assess all estuarine types and to provide clear distinction of conditions among estuaries. The data and information collected included magnitude, timing, and frequency of occurrence of extreme conditions during the annual cycle. For example, Chlorophyll $a$ data considers the concentrations during the largest bloom (e.g. winter-spring bloom), the spatial area over which the highest concentrations occur, and the frequency with which blooms recur (e.g., annual, persistent, episodic).

Response ranges were developed from U.S. estuarine data and were selected to be simple to use and to distinguish the magnitude of eutrophic symptoms among estuaries. For example, Chlorophyll a and dissolved oxygen concentrations were assigned to High, Medium and Low categories based on observations as well as discussions with local investigators. Chlorophyll a bloom concentrations were assigned as Low $=0-5 \mu \mathrm{g}^{-1}$, Medium $=>5-20 \mu \mathrm{g} \mathrm{l^{-1 }}$, High $=>20-60 \mu \mathrm{g}^{-1}$ and Hypereutrophic $=>60 \mu \mathrm{g} \mathrm{1^{-1 }}$. Dissolved oxygen conditions were assigned as Anoxic $=0 \mathrm{mg} \mathrm{l}^{-1}$, Hypoxic $=>0-2 \mathrm{mg} \mathrm{l}^{-1}$, Biologically Stressful $=>2-5 \mathrm{mg}^{-1}$ (Table 1; for full detail of criteria see Bricker et al. 1999 or Bricker et al. 2003). Although some response criteria may not distinguish among estuaries within a region, they are intended to distinguish among estuaries on a broad geographic basis. However, these ranges did not work universally for the 138 systems and the NEEA Update Program is working to re-evaluate the ranges and develop criteria that will more accurately characterize conditions by type of estuary (where type classification is determined primarily by similar physical and hydrologic characteristics).

For epiphyte and macroalgal abundances, and nuisance and toxic algal blooms, a different approach was used because there is no standard measure for these variables. For these indicator variables, NEEA participants were asked simply if they were or were not a problem in their system (e.g., nuisance and toxic blooms causing fish kills, macroalgae causing losses of SAV or smothering of bivalves).

Data for conditions and trends in 138 U.S. estuaries and the Mississippi/ Atchafalaya River Plume were collected in a series of questionnaires, site visits, and regional workshops (NOAA 1996, 1997a-c, 1998). Data were collected by salinity zone (Tidal Fresh $=0-0.5 \mathrm{ppt}$, Mixing Zone $=0.5-25 \mathrm{ppt}$, Seawater Zone $\geq 25 \mathrm{ppt}$ ) for each system, providing a basis for comparison among the highly varied systems. About 400 participants from academia, and state, federal, and local agencies provided information and data. A reliability assessment (self-assigned) ranging from 'highly confident' to 'speculative' was offered for each response since the information varies from statistically tested scientific data to general observations. The final assessment also has an associated reliability assessment based on the reliability of data and information used in the analysis. 


\section{The NEEA/ASSETS assessment methodology}

The NEEA model (Bricker et al. 1999), and recent modifications described in the Assessment of Estuarine Trophic Status (ASSETS; Bricker et al. 2003), uses a Pressure-State-Response framework to assess eutrophication in three component parts:

- Overall human influence (OHI) on development of conditions (Pressure),

- Overall eutrophic conditions (OEC) within a water body (State), and

- Determination of future outlook (DFO) for conditions within the system (Response).

Aspects of each component use a decision logic approach to combine data and information into single multi-dimensional descriptors and matrices are used to combine two components into a single descriptor for each of the three components.

\section{Pressure - overall human influence (OHI)}

The 'Pressure' component of the assessment is designed to determine the influence of human related inputs relative to the natural tendency of a system to either retain or flush nutrients (i.e. susceptibility). This component is determined by combining in a matrix an estimation of susceptibility of a system, and the level of nutrient inputs from the watershed. Participants in the NEEA used watershed nutrient model estimates (SPARROW; Smith et al. 1997), watershed population density and other demographic data in the Coastal Assessment and Data Synthesis (CADS 1999) to estimate inputs. These were divided into High, Medium, and Low categories. Hydrologic and physical data from CADS (1999) was used to determine susceptibility. In a logic decision approach, the dilution potential takes into account vertical stratification and dilution volume which are dependent upon the stratification status. Similarly, the flushing potential is estimated from tide range and the ratio of freshwater inflow to the volume of the estuary. The final susceptibility estimate of High, Medium, or Low is determined in a matrix combining the dilution and flushing values (Bricker et al. 1999).

In ASSETS, improvements were made to the original methodology by applying a simple model to better estimate the level of human related nutrient inputs to the system. The model compares anthropogenic nutrient loading and natural background concentrations and also factors in potential nutrient inputs from oceanic sources thus addressing the question of whether management measures would be successful. The results of the model calculation, essentially a ratio of land or human related inputs to oceanic inputs, are assigned one of five categories: High, Moderately High, Moderate, Moderately Low, and Low and are used in the matrix with the susceptibility measure in place of the nutrient load estimates that were used in the NEEA. For a full description of 
model development and use of the matrix to estimate the level of human influence see Bricker et al. (2003).

State - overall eutrophic condition (OEC)

To determine overall eutrophic condition, six variables were selected from the original 16 that were characterized in the NEEA (Table 1; Bricker et al. 1999). These were divided into two groups: primary or early stage symptoms (chlorophyll a, epiphytes, macroalgae), and secondary or well developed eutrophication symptoms (dissolved oxygen, Submerged Aquatic Vegetation (SAV) loss, harmful algal bloom occurrence). In the original NEEA, a logic decision approach was used to determine the level for each variable within each estuarine salinity zone. The level for an indicator is a combined value of the extreme concentration or condition of the variable (e.g. bloom concentration of Chl $a$, or lowest concentration of dissolved oxygen), the spatial area over which the extreme conditions occur, and the frequency with which it is observed (e.g. annually, periodically, episodically; Table 2). The separate salinity zone results are then combined to give a weighted average value for the

Table 2. Logic decision approach for Chlorophyll $a$ level of expression (Bricker et al. 1999).

\begin{tabular}{lllll}
\hline IF & AND & AND & THEN & \\
\hline Concentration & Spatial coverage & Frequency & Expression & Value \\
Hypereutrophic or High & High & Periodic & High & 1 \\
& Moderate & Periodic & High & 1 \\
& Low & Periodic & Moderate & 0.5 \\
& Very Low & Periodic & Moderate & 0.5 \\
& High & Episodic & High & 1 \\
& Moderate & Episodic & Moderate & 0.5 \\
& Low/Very Low & Episodic & Low & 0.25 \\
& Any spatial coverage & Unknown & Flag A & 0.5 \\
& Unknown & Any frequency & Flag A & 0.5 \\
Medium & High & Periodic & High & 1 \\
& Moderate & Periodic & Moderate & 0.5 \\
& Low/Very Low & Periodic & Low & 0.25 \\
& High & Episodic & Moderate & 0.5 \\
& Mod/Low/Very Low & Episodic & Low & 0.25 \\
& Any spatial coverage & Unknown & Flag A & 0.5 \\
& Unknown & Any frequency & Flag A & 0.5 \\
Low & Any spatial coverage & Any frequency & Low & 0.25 \\
Unknown & Unknown & Unknown & Not included in cal- \\
& & & culation at zone level \\
\hline
\end{tabular}

Chlorophyll $a$ Level of Expression Determination.

Spatial coverage and frequency of occurrence are used to determine the level of expression for each salinity zone and are then aggregated up to the estuary level. 
estuary which is given a numerical value that is then converted to a categorical rating (i.e. High, Moderate, Low).

The overall primary symptom level is determined by averaging the values for Chla, epiphytes, and macroalgae; whereas the highest of the three secondary symptoms (dissolved oxygen, loss of SAV, nuisance and/or toxic bloom occurrences) is selected based on the assumption that these symptoms indicate a well developed problem. These values are combined to determine an overall rating of eutrophic conditions for the estuary (Figure 1). Assessment results show that nutrient related water quality problems occur on a national basis (Figure 2).

Recent modifications have been made that allow the use of data rather than 'expert knowledge' for Chl $a$ and dissolved oxygen. These variables are measured in a standard manner and statistical criteria were developed to quantify them in a more robust manner while staying true to the intent of

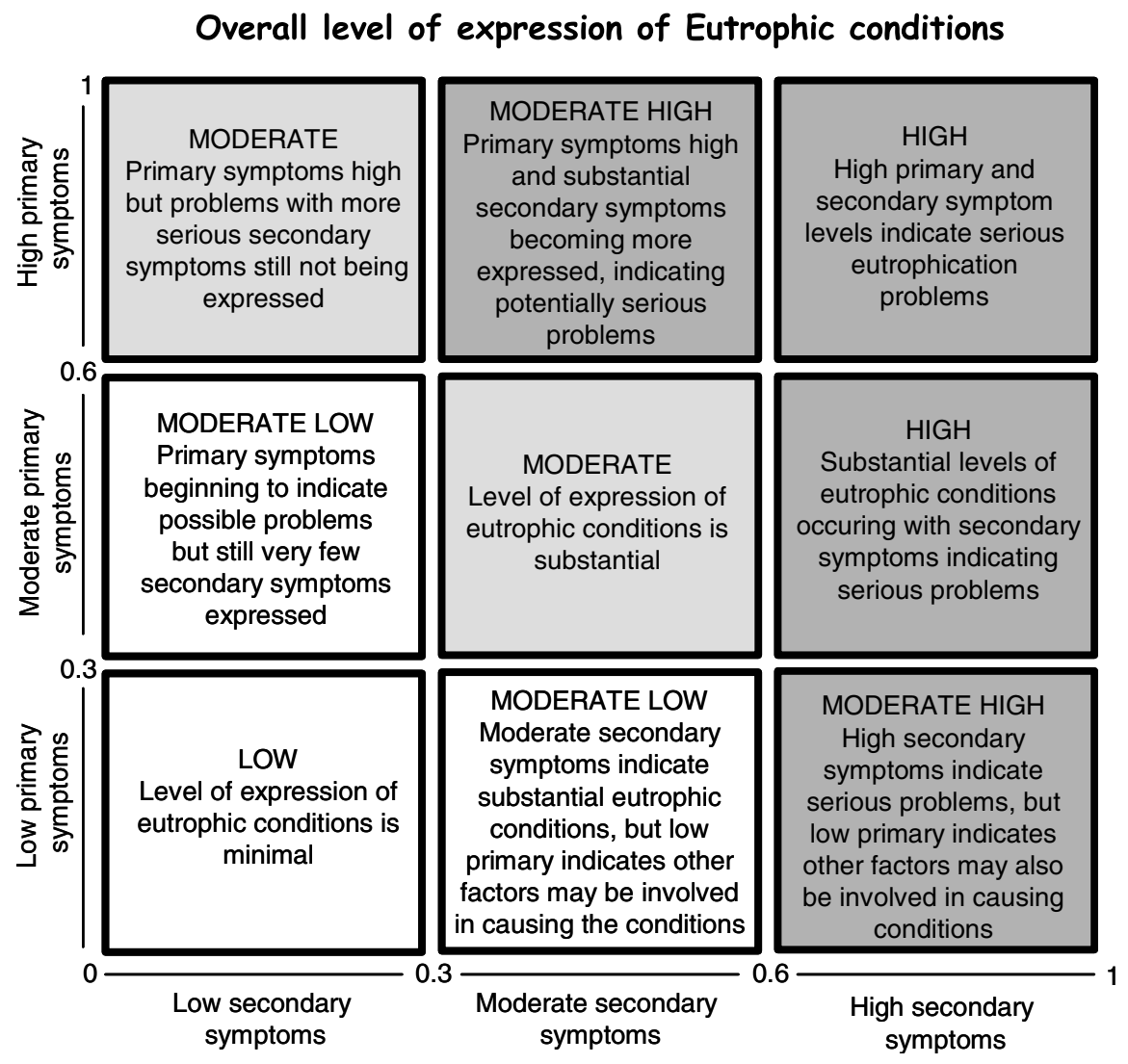

Figure 1. Matrix for determination of overall eutrophic condition from primary and secondary symptom levels (from Bricker et al. 2003). 


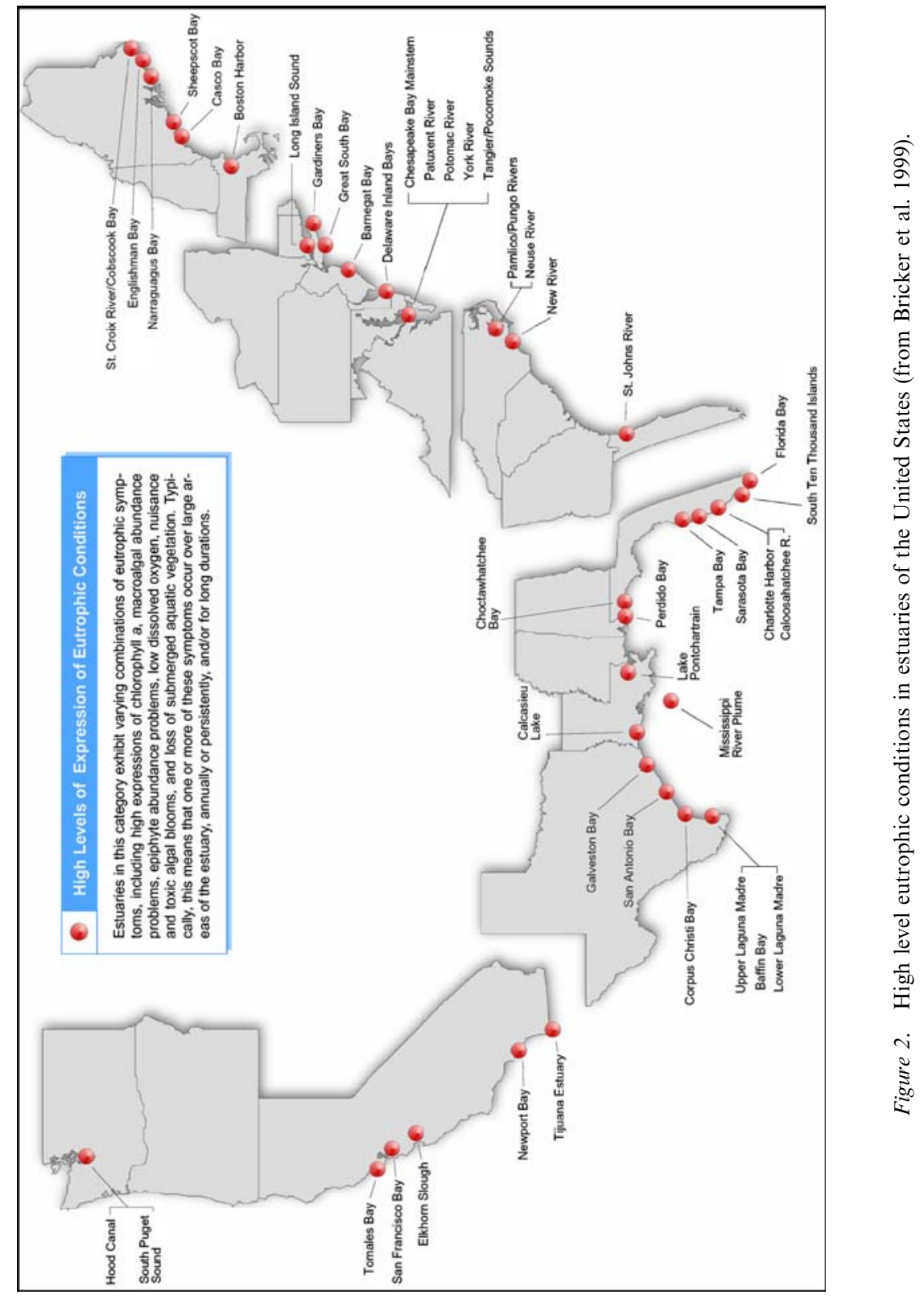


reporting extreme concentrations. The approach used is to determine 90th percentile concentration during the annual cycle for Chlorophyll $a$ and the 10th percentile for dissolved oxygen (Bricker et al. 2003). These are then converted to the categorical ratings using the thresholds of the NEEA (i.e. for Chl $a$; Low $=0-5 \mu \mathrm{g}^{-1}$, Medium $\geq 5-20 \mu \mathrm{g} 1^{-1}$, High $=\geq 20-60 \mu \mathrm{g}^{-1}$ and Hypereutrophic $\geq 60 \mu \mathrm{g}^{-1}$ ) and used in the same manner as described above. Additional improvements to the original 'expert knowledge' methodology have also been proposed for macroalgae, and submerged aquatic vegetation based on comparison of potential area of colonization and effective colonized area. Presently these are still determined heuristically. Due to the lack of data on a national basis, epiphytes are no longer used as an indicator.

\section{Response - determination of future outlook (DFO)}

The Response component or future outlook is designed to estimate changes that might occur given predicted changes in nutrient input to a system. Like the other components this is determined by a matrix that combines susceptibility of the system with expected future changes in nutrient loads. Predictions of nutrient loading (increase, decrease, unchanged) are based on predicted population increase, planned management actions and expected changes in watershed uses. Results show that 86 systems were expected to become worse and only eight to improve from the early 1990s to the year 2020 (Bricker et al. 1999). The NEEA Update anticipated for late in 2006 will provide an interim report of changes over a decade, from the early 1990 s to the early 2000 s.

\section{Synthesis - grouping pressure, state and response indicators}

An additional modification to the original method (ASSETS; Bricker et al. 2003) combines the OEC, OHI, and DFO into a single overall score falling into one of five categories: high, good, moderate, poor, or bad. These categories conform to the EU Water Framework Directive (EUWFD; 2000/60/ EC) and the framework provides a scale for setting eutrophication related reference conditions for different types of systems (e.g., Bettencourt et al. 2004).

\section{Additional modifications: NEEA update program}

Further modifications that are presently being pursued in the NEEA update program include the development of a type classification based on physical and hydrologic characteristics using the Deluxe Integrated System for Clustering Operations (DISCO) tool (Smith and Maxwell 2002). Preliminary results are promising (Smith et al. 2004) and will be used to determine type specific ref- 
erence conditions and thresholds for desirable/undesirable conditions for indicator variables. Additionally, indicator variables are being evaluated by type to ensure that all types of estuaries are assessed with indicators that are relevant. For instance, in types where there is no SAV under natural conditions, an alternative indicator will be used.

A socio-economic/human use indicator is being developed where changes in fish catch rate are related to changes in water quality in the manner of Lipton and Hicks (1999, 2003) and Mistiaen et al. (2003). Preliminary analysis of Long Island Sound data shows that as nitrogen inputs decrease, dissolved oxygen and recreational catch of Striped Bass increase. The increase in catch is shown to be related to changes in oxygen when other influences (e.g. fishermen avidity and experience, temperature, changes in fish stock) are accounted for (Mason et al. 2004).

Finally, an online tool is being developed that can be used by scientists and managers to assess eutrophication and compare with other systems of similar types from the US and internationally (http://www.eutro.org). Results will be stored so that trends can be developed and tracked online with successive assessments. Additionally, the site provides publications that describe: the legislative context nationally and internationally that drive assessment and management, the general concept of the eutrophication issue, the development of the NEEA/ASSETS methodology, and programs supporting monitoring, assessment, management and research of nutrient related eutrophication in US and EU estuaries and coastal waters.

\section{An integrated assessment of the causes and consequences of hypoxia in the northern Gulf of Mexico}

The integrated assessment (IA) of the causes and consequences of hypoxia in the northern Gulf of Mexico (CENR 2000) is an example of a watershed approach to evaluating options for management action. While this approach is proving to be effective on this massive scale, it can be as effective, in fact more tractable, on smaller scales more typical of estuarine watersheds. The Mississippi River system ranks among the world's top 10 rivers in length, freshwater discharge, and sediment delivery and drains $41 \%$ of the contiguous United States (Figure 3). This massive river system discharges to the Louisiana/Texas continental shelf producing the largest zone of oxygen-depleted coastal waters (hypoxia) in the western Atlantic Ocean. Recurring summer hypoxia in the northern Gulf of Mexico has received considerable scientific and policy attention because of potential ecological and economic impacts from this very large zone of low oxygen, and because of the implications for management within its massive watershed (CENR 2000; Mitsch et al. 2001; Task Force 2001; Rabalais et al. 2002). In 1998, the Congress passed and the President signed into law the Harmful Algal Bloom and Hypoxia Research and Control Act (HABHRCA), which among other things called for an Integrated 


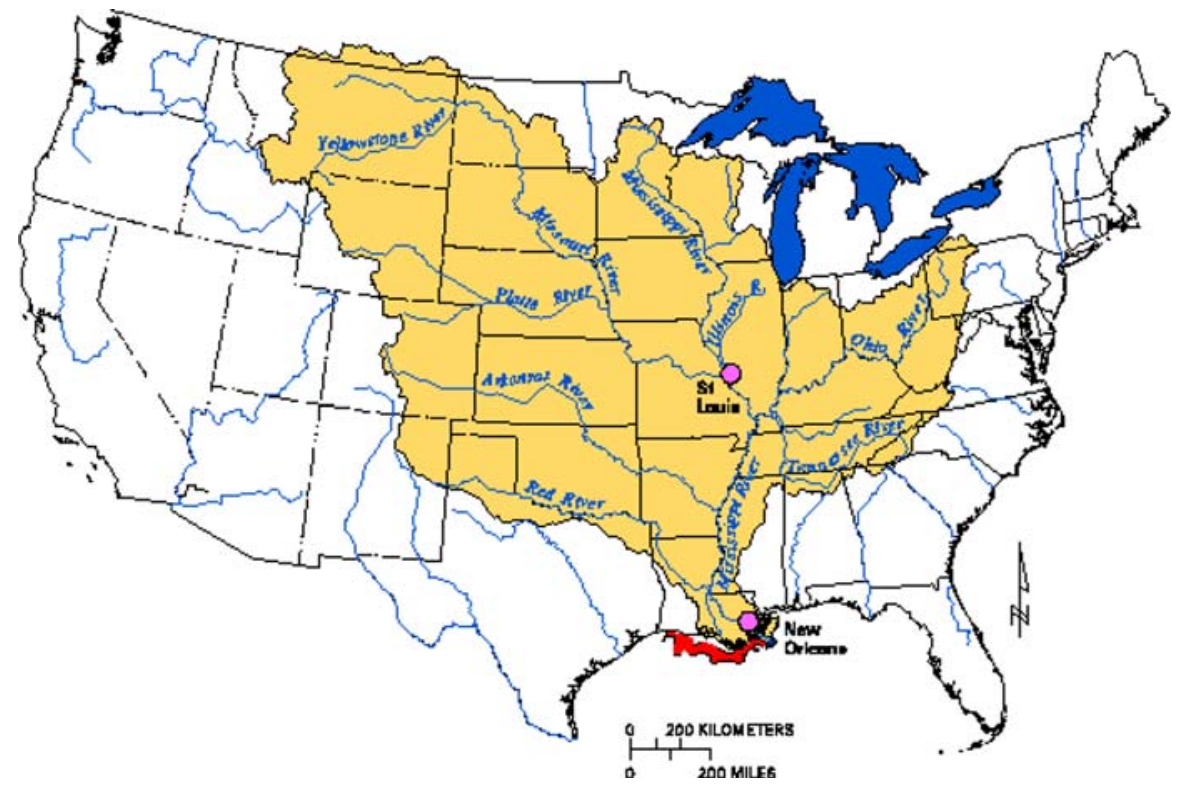

Figure 3. Mississippi/Atchafalaya River Basin and Gulf of Mexico Hypoxia (Rabalais et al. 2002).

Assessment of its causes and consequences in support of an Action Plan to reduce the size of the hypoxic zone. The analysis followed the Integrated Assessment approach:

1. Define the policy relevant question around which the assessment is to be performed. This was established early in the HABHRCA language - 'assess the causes and consequences of hypoxia in the northern Gulf of Mexico.'

2. Document the status and trends of appropriate environmental, social, and economic conditions related to the issue. This is a value-independent description of current conditions and, to the extent possible, the historical trends in those properties.

3. Describe the environmental, social, and economic causes and consequences of those trends. This often includes simulation, statistical, and other explanatory models and analyses. Again, these descriptions are fact-based although subject to analysis and interpretation.

4. Provide forecasts of likely future conditions under a range of policy and/or management actions. This can be quantitative forecasts from models or other trend analysis tools. These are subject to considerable scientific evaluation and interpretation.

5. Provide technical guidance for the most cost effective means of implementing each of those options. These efforts are designed to provide those who are responsible for implementation the menu of approaches available 
to them, along with some evaluation of their potential for success and costeffectiveness.

6. Provide an assessment of the uncertainties associated with the information generated for the above steps and outline key monitoring, research, and modeling needs to improve future assessments in this area.

To form a solid basis for the IA, six technical reports were commissioned (Brezonik et al. 1999; Diaz and Solow 1999; Doering et al. 1999; Goolsby et al 1999; Mitch et al. 1999; Rabalais et al. 1999) and subjected to independent peer review, followed by formal public comment (Rabalais et al 2002). These reports documented the ecological and economic extent, characteristics, causes, and effects of Gulf hypoxia; the flux and sources of nutrients in the Mississippi River system; the effects of reducing nutrient loads on waters within the basin and in the Gulf; methods to reduce nutrient loads; and the social and economic costs and benefits of methods to reduce nutrient loads. Description of the production, peer review, and public comment processes, along with the six reports, the Integrated Assessment, public comments, and responses to those comments are available at: http://www.nos.noaa.gov:80/Products/pubs_hypox.html.

Regions of oxygen concentrations below $2 \mathrm{mg}^{-1}$ (hypoxia) that form off the Louisiana coast each spring and summer increased from an average of $8300 \mathrm{~km}^{2}$ in 1985-1992 to over $16,000 \mathrm{~km}^{2}$ in 1993-2001 (Rabalais et al. 2002), and reached a record $22,000 \mathrm{~km}^{2}$ in 2002 (Figure 4). The IA concluded that the almost threefold increase in nitrogen load to the Gulf (Goolsby et al. 1999) has been the primary external driver of increased hypoxia (Brezonik et al. 1999;

Areal Extent of Hypoxic Zone 1985 - 2001

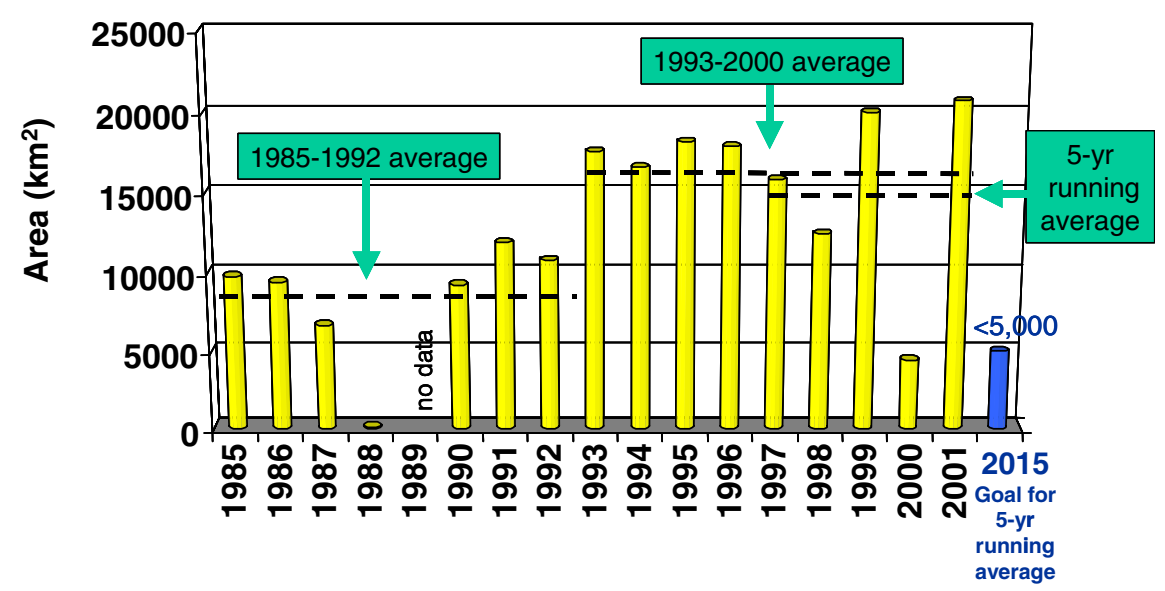

Figure 4. Area of hypoxia in the northern Gulf of Mexico, including various 5 year running averages and the Action Plan goal of $5000 \mathrm{~km}^{2}$ (Rabalais et al. 2002). 
Rabalais et al. 1999). This riverine nitrogen input stimulates coastal algal production and the subsequent settling of organic matter below the pycnocline. Because the pycnocline inhibits vertical oxygen flux, decomposition of organic matter below the pycnocline consumes oxygen faster than it is replenished, resulting in declining oxygen concentrations during the period of stratification. Two key questions were asked during development of policies to reduce, mitigate, and control Gulf hypoxia (Task Force 2001; Rabalais et al. 2002). The first was: 'When did large-scale hypoxia start in the Gulf of Mexico?' Knowing the answer to this question is important both for understanding its underlying causes and for identifying reasonable and practical goals for reducing its size. During development of the initial IA, the answer to this question was based on sporadic historical data and selected sediment core records, and it could only suggest that significant changes in bottom water oxygen conditions likely took place after the 1950s. The second question debated during development of the Action Plan was: 'What nitrogen load reduction would be needed to reach the societal goal set for hypoxia?' Model analysis during the development of the initial IA indicated that reducing $\mathrm{N}$ loads by $30-50 \%$ should increase oxygen concentrations in the bottom waters by $35-50 \%$ (Bierman et al. 2001; Brezonik et al. 1999).

The IA also identified the most significant nitrogen sources within the basin as being agricultural non-point sources originating in midwestern states. Ninety percent of the nitrate inputs to the Gulf come from non-point sources; $74 \%$ from agricultural non-point sources; and $56 \%$ of the nitrate enters the system north of Ohio River. Thus, the IA and resulting Action Plan focused on addressing these non-point sources.

Mitsch et al. $(1999,2001)$ reviewed the range of methods and technologies available to reduce $\mathrm{N}$ loads, including those from point and non-point sources, and concluded that the most effective methods are those that keep nitrogen on agricultural lands and those that encourage denitrification within the watershed (Figure 5). Of the 2.5 million metric tons of $\mathrm{N}$ that could potentially be prevented from reaching the Gulf, $24 \%$ could potentially result from denitrification losses in wetlands and riparian buffers; whereas $73 \%$ could potentially result from improved nitrogen management on farm lands. Only $2-3 \%$ would be reduced from upgrading all sewage treatment plants.

Doering et al. (1999) evaluated costs associated with the various nitrogen control and mitigation options. For example, they concluded that agricultural practices (other than reduced fertilizer use) to reduce the loss of nitrogen at the edge of the field would cost $\$ 0.88$ per $\mathrm{kg}$ of Nitrogen for a $20 \%$ loss reduction and $\$ 3.37$ per $\mathrm{kg}$ of nitrogen for a $40 \%$ loss reduction. The higher costs per unit $\mathrm{N}$ loss reflect the fact that achieving $40 \%$ loss reductions would require retiring more productive lands than a $20 \%$ reduction. The costs associated with achieving a comparable $20 \% \mathrm{~N}$ load reduction from reduced fertilizer applications is $\$ 0.69 /$ unit $\mathrm{N}$ load, from construction and operation of 5 million acres of wetlands is $\$ 8.90 /$ unit $\mathrm{N}$ load, and from construction of 19 million acres of riparian buffers is $\$ 26.03 /$ unit $\mathrm{N}$ load. 


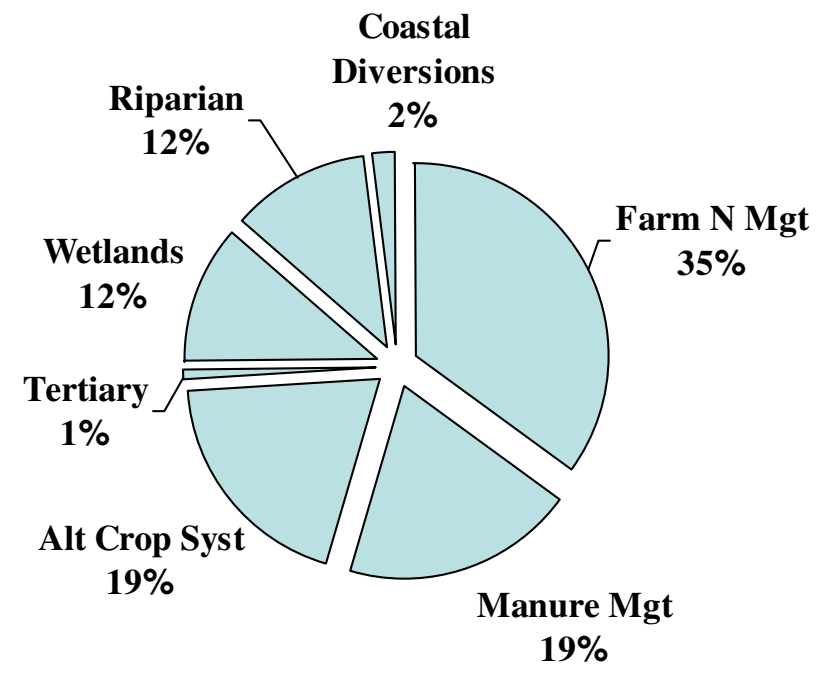

Figure 5. Potential sources of $\mathrm{N}$ load reduction. Total potential reduction from all sources is 2.5 million metric tons per year. Data Source: Mitsch et al. (1999, 2001), CENR (2000).

It is interesting to note that, while gross costs per unit $\mathrm{N}$ load reduction vary considerably from $\$ 0.69$ to $\$ 0.88$ to $\$ 8.90$ for reduced fertilizer use, other improved agricultural practices, and wetland construction respectively, the net costs ( $\$ 0.67, \$ 0.80, \$ 1.00$, respectively) are closer to each other. These net costs include economic benefits such as reduced fertilizer purchases and wetland benefits such as flood control, wildlife protection, and recreation. These relatively comparable unit costs across the three major control approaches gave the Task Force and related agencies flexibility in implementation. Fortunately, recent reanalysis (McIsaac et al. 2001, 2002) of the effects of potential management actions on nitrogen loads from the Mississippi River Basin suggest that those reductions might be even easier to achieve than estimated in the original studies supporting the Action Plan (Doering et al. 1999).

\section{Analysis and summary}

Clark and Majone (1985) outlined four criteria for evaluating integrated assessments - Technical adequacy, Value, Legitimacy, and Effectiveness. The Gulf hypoxia IA and the National assessment (NEEA) score well on all four criteria. 'Technical adequacy' was achieved in the IA through the independent peer review of the six background technical reports and subsequent publications in the primary literature. NEAA was built from the peer reviewed literature, a formal process for integrating expert opinion, and peer review of the overall product. 'Value' in the IA was established by responding directly to 
directives of the HABHRCA statute and the guidance and expectations of the Task Force responsible for creating an action plan. The NEEA, published in 1999 effectively raised the profile of this national issue in Congress, with federal and state agencies, and in stimulation of a comprehensive evaluation by the National Research Council (NRC 2000). 'Legitimacy' in the IA was established by engaging a wide range of stakeholders in the development and review of the IA and background reports, as well as through formal public comment, facilitated and open science meetings, and participation in seven public meetings of the Task Force. The participation of most U.S. scientists and many policy makers with expertise and experience in coastal eutrophication ensured legitimacy for the NEEA.

According to Clark and Majone (1985), 'Effectiveness' is best measured by two factors - did the assessment make a difference in a policy outcome and/or did it influence how policy makers understand the problem. The first and most obvious measure of effectiveness of the IA is that it led to an Action Plan (Task Force 2001) that was endorsed by eight Federal Agencies, nine Basin States, and two Tribes and delivered to the President and the Congress in 2001. The second measure is that the IA has changed the way scientists and policy makers think about and discuss options for dealing with excess nutrient loads to the Gulf of Mexico, and to some extent, the rest of agriculturally dominated coastal watersheds. NEEA similarly changed the focus of how U.S. agencies and scientists viewed the problem of coastal eutrophication, as well as stimulating continued dialog in both Congress and the administration (e.g., HABHRCA, Ocean Commission 2004).

Morgan and Dowlatabadi (1996) suggest that assessments should be iterative and include new information as it becomes available. Just as the National Estuarine Eutrophication Assessment is being modified, updated, and improved, new information is becoming available for the Gulf hypoxia assessment, in time for the 5 year reassessment called for in the Action Plan (Task Force 2001). While modeling and other analyses were sufficient to allow the Task Force to establish a goal of reducing the average size of the hypoxic region to below $5000 \mathrm{~km}^{2}$ by reducing $\mathrm{N}$ loads by $30 \%$, subsequent modeling efforts helped refine those estimates. These more recent analyses (Scavia et al. 2003, 2004) compared three very different models to reach the consensus that large-scale hypoxia likely did not start in the Gulf of Mexico until the mid1970s and that the $30 \%$ nitrogen load reduction called for in the Action Plan may not be sufficient to reach the plan's goal. Load reductions of $35-45 \%$ are likely to be needed to reach the hypoxia goals in most years.

These two examples provide templates for different approaches to assessing coastal eutrophication. The national assessment was able to establish the overall state of the nation with respect to coastal eutrophication even though data were not uniformly available or comprehensively obtained. The use of expert knowledge within a consistent and comprehensive framework produced information upon which Federal policy makers could form a basis for action. It also provided a sense of status and trends, with tentative notions of futures, for 
specific estuaries and regions, and it formed a basis for a more comprehensive assessment that addressed causes and potential remedies at similar national scales (CENR 2003). Continued improvements to the approach including development of type specific indicators and thresholds and identification and apportionment of watershed nutrient sources will result in more accurate assessments of conditions and more targeted recommendations for management.

The second approach focused on a particular watershed, albeit the largest in the United States. This focus on the specific causes and consequences of nutrient pollution for this watershed and receiving water enabled targeted options for restoration, as opposed to the more general recommendations of the national assessment. Similar approaches at smaller scales, such as individual estuarine watersheds, are likely to provide a more effective basis for managing coastal eutrophication.

\section{References}

Bettencourt A., Bricker S.B., Ferreira J.G., Franco A., Marques J.C., Melo J.J., Nobre A., Ramos L., Reis C.S., Salas F., Silva M.C., Simas T. and Wolff W. 2004. Typology and Reference Conditions for Portuguese Transitional and Coastal Waters Development of guidelines for the application of the European Union Water Framework Directive. Instituto da Agua (INAG)-Institute of Marine Science (IMAR), Lisbon. http://www.ecowin.org/ticor/documents/TICOR\%20book.pdf.

Bierman Jr. V.J., Hinz S.C., Wiseman Jr. W.J., Rabalais N.N. and Turner R.E. 2001 Forecasting hypoxia in the Gulf of Mexico: Responses to nutrient loadings from the Mississippi River Basin. Presentation at Coastal Zone 01, July 18, 2001, Cleveland.

Boynton W.R., Murray L., Hagy J.D., Stokes C. and Kemp W.M. 1996. A comparative analysis of eutrophication patterns in a temperate coastal lagoon. Estuaries 19(2B): 408-421.

Brezonik P.L., Bierman Jr. V.J., Alexander R., Anderson J., Barko J., Dortch M., Hatch L., Hitchcock G.L., Keeney D., Mulla D., Smith V., Walker C., Whitledge T. and Wiseman Jr. W.J. 1999. Effects of Reducing Nutrient Loads to Surface Waters within the Mississippi River Basin and the Gulf of Mexico. Topic 4 Report for the Integrated Assessment of Hypoxia in the Gulf of Mexico. NOAA Coastal Ocean Program Decision Analysis Series No. 18, National Oceanic and Atmospheric Administration, Coastal Ocean Program, Silver Spring.

Bricker S., Matlock G., Snider J., Mason A., Alber M., Boynton W., Brock D., Brush G., Chestnut D., Claussen U., Dennison W., Dettmann E., Dunn D., Ferreira J., Flemer D., Fong P., Fourqurean J., Hameedi J., Hernandez D., Hoover D., Johnston D., Jones S., Kamer K., Kelty R., Keeley D., Langan R., Latimer J., Lipton D., Magnien R., Malone T., Morrison G., Newton J., Pennock J., Rabalais N., Scheurer D., Sharp J., Smith D., Smith S., Tester P., Thom R., Trueblood D. and Van Dolah R. 2004. National Estuarine Eutrophication Assessment Update: Workshop summary and recommendations for development of a long-term monitoring and assessment program. Proceedings of a workshop September 4-5 2002, Patuxent Wildlife Research Refuge, Laurel, Maryland. National Oceanic and Atmospheric Administration, National Ocean Service, National Centers for Coastal Ocean Science. Silver Spring. http:// www.eutro.org/documents/dldo.pdf.

Bricker S.B., Clement C.G., Pirhalla D.E., Orlando S.P. and Farrow D.R.G. 1999. National Estuarine Eutrophication Assessment. Effects of Nutrient Enrichment in the Nation's Estuaries. NOAA, National Ocean Service, Special Projects Office and National Centers for Coastal Ocean Science, Silver Spring. http://www.spo.nos.noaa.gov/projects/cads/nees/Eutro_Report.pdf. 
Bricker S.B., Ferreira J.G. and Simas T. 2003. An integrated methodology for assessment of estuarine trophic status. Ecol. Model. 169: 39-60. http://www.coastalscience.noaa.gov/documents/assets.pdf.

Burkholder J.M., Noga E.J., Hobbs C.H. and Glasgow H.B. Jr. 1992a. New 'phantom' dinoflagellate is the causative agent of major estuarine fish kills. Nature 358: 407-410.

Burkholder J.M., Mason K.M. and Glasgow H.B. Jr. 1992b. Water-column nitrate enrichment promotes decline of eelgrass Zostera marina: evidence from seasonal mesocosm experiments. Mar. Ecol. Prog. Ser. 81: 163-178.

Coastal Assessment and Data Synthesis System (CADS). 1999. NOAA, National Ocean Service, Special Projects Office, Silver Spring. http://www.cads.nos.noaa.gov.

CENR 2003. An Assessment of Coastal Hypoxia and Eutrophication in U.S. Coastal Waters. National Science and Technology Council Committee on Environment and Natural Resources, Washington. http://www.nccos.noaa.gov/publications/hypoxia.pdf.

CENR 2000. Integrated Assessment of Hypoxia in the Northern Gulf of Mexico. National Science and Technology Council Committee on Environment and Natural Resources, Washington.

Clark W.C. and Majone G. 1985. The critical appraisal of scientific enquiries with policy implications. Science, Technology and Human Values 10(3): 6-19.

COAST. 2003. European Union Common Implementation Strategy Working Group 24 Final Draft Guidance on Coastal and Transitional Waters. European Union Water Directors, Copenhagen. http://www.eutro.org/documents/wfd $\% 20$ cis $2.4 \% 20$ (coast) $\% 20$ guidance $\% 20$ on $\%$ 20tcw.pdf.

Dennison W.C., Moore K.A. and Stevenson J.C. 1992. Chapter III: SAV habitat requirements development. In: Batuik R.A., Orth R.J., Moore K.A., Dennison W.C., Stevenson J.C., Staver L.W., Carter V., Rybicki N.B., Hickman R.E., Kollar S., Bieber S. and Heasly P. (eds), Chesapeake Bay Submerged Aquatic Vegetation Habitat Requirements and Restoration Targets: A Technical Synthesis. US Environmental Protection Agency, Chesapeake Bay Program, Annapolis.

Diaz R.J. and Solow A. 1999. Ecological and economic consequences of hypoxia. Topic 2. Gulf of Mexico Hypoxia Assessment. NOAA Coastal Ocean Program Decision Analysis Series. National Oceanic and Atmospheric Administration, Coastal Ocean Program, Silver Spring.

Doering, O.C. et al. 1999. Evaluation of the economic costs and benefits of methods for reducing nitrogen loads to the Gulf of Mexico. National Oceanic and Atmospheric Administration, Coastal Ocean Program Decision Analysis Series No. 20, Silver Spring.

European Commission Water Framework Directive 2000/60/EC (WFD) http://www.europa.eu.int/ comm/environment/water/water-framework/index_en.html.

Goolsby D.A., Battaglin W.A., Lawrence G.B., Artz R.S., Aulenbach B.T., Hooper R.P., Keeney D.R. and Stensland G.J. 1999. Flux and Sources of Nutrients in the MississippiAtchafalaya River Basin, Topic 3 Report for the Integrated Assessment of Hypoxia in the Gulf of Mexico. NOAA Coastal Ocean Program Decision Analysis Series No. 17. National Oceanic and Atmospheric Administration, Coastal Ocean Program, Silver Spring.

Hinga K.R., Stanley D.W., Klein C.J., Lucid D.T. and Katz M.J. (eds) 1991. The National Estuarine Eutrophication Project: Workshop Preceedings. National Oceanic and Atmospheric Administration and the University of Rhode Island Graduate School of Oceanography, Rockville http://www.eutro.org/documents/hinga\%201991.pdf.

Howarth R.W., Anderson D., Cloern J., Elfring C., Hopkinson C., Lapointe B., Malone T., Marcus N., McGlathery K., Sharpley K. and Walker D. 2000. Nutrient pollution of coastal rivers, bays, and seas. Issues Ecol. 7: 1-15.

Howarth R., Marino R. and Scavia D. 2003. Nutrient Pollution in Coastal Waters - Priority Topics for an Integrated National Research Program for the United States. United States Department of Commerce, National Oceanic and Atmospheric Administration, National Ocean Service, National Centers for Coastal Ocean Science. Silver Spring.

Jaworski N.A. 1981. Sources of nutrients and the scale of eutrophication problems in estuaries. In: Neilson B.J. and Cronin L.E. (eds.), Estuaries and Nutrients, Humana Press, Clifton, pp. 83-110. 
Lapointe B.E. and Matzie W.R. 1996. Effects of stormwater nutrient discharges on eutrophication processes in nearshore waters of the Florida Keys. Estuaries 19(2B): 422-435.

Lipton D.W. and Hicks R. 2003. The cost of stress: low dissolved oxygen and recreational striped bass (Morone saxatilis) fishing in the Patuxent River. Estuaries 26: 310-315.

Lipton D.W. and Hicks R. 1999. Linking water quality improvements to recreational fishing values: the case of Chesapeake Bay striped bass. In: Evaluating the Benefits of Recreational Fisheries. Fisheries Centre Research Reports 7(2). University of British Columbia.

Mason A., Lipton D.W. and Bricker S.B. 2004. Improving indicators of water quality degradation impacts for management of estuarie and coastal waters, p. 102. In American Society of Limnology and Oceanography and The Oceanography Society 2004 Ocean Research Conference Abstract Book. February 15-20, 2004. Hawaii Convention Center, Honolulu. http://www.aslo.org/honolulu2004/files/aslo-tos-2004-abstracts.pdf.

McIssac G.F., David M.B., Gertner G.Z. and Goolsby D.A. 2001. Nitrate flux in the Mississippi River. Nature 414: 166-167.

McIssac G.F., David M.B., Gertner G.Z. and Goolsby D.A. 2002. Relating net nitrogen input in the Mississippi River basin to nitrate flux in the Lower Mississippi River: a comparison of approaches. J. Environ. Quality 31: 1610-1622.

Morgan M.G. and Dowlatabadi H. 1996. Learning from integrated assessment of climate change. Climatic Change 34: 337-368.

Mitsch W.J., Day Jr. J.W., Gilliam J.W., Groffman P.M., Hey D.L., Randall G.W. and Wang N. 1999. Reducing Nutrient Loads, Especially Nitrate-Nitrogen, to Surface Water, Ground Water, and the Gulf of Mexico. Topic 5 Report for the Integrated Assessment of Hypoxia in the Gulf of Mexico. NOAA Coastal Ocean Program Decision Analysis Series No. 19. National Oceanic and Atmospheric Administration, Coastal Ocean Program, Silver Spring.

Mitsch W.J., Day J.W. Jr., Gilliam J.W., Groffman P.M., Hey D.L., Randall G.W. and Wang N. 2001. Reducing nitrogen loading to the Gulf of Mexico from the Mississippi River basin: strategies to counter a persistent ecological problem. BioScience 15: 373-388.

Mistiaen J.A., Strand I.E. and Lipton D.W. 2003. Effects of environmental stress on blue crab (Callinectes sapidus) harvests in Chesapeake Bay tributaries. Estuaries 26: 316-322.

National Oceanic and Atmospheric Administration (NOAA). 1996. NOAA's Estuarine Eutrophication Survey. Volume 1: South Atlantic Region. National Oceanic and Atmospheric Administration, National Ocean Service, Office of Ocean Resources Conservation and Assessment. Silver Spring http://www.eutro.org/documents/south\%20atlantic\%20regional\%20report.pdf.

National Oceanic and Atmospheric Administration (NOAA). 1997a. NOAA's Estuarine Eutrophication Survey. Volume 2: Mid-Atlantic Region. National Oceanic and Atmospheric Administration, National Ocean Service, Office of Ocean Resources Conservation and Assessment. Silver Spring http://www.eutro.org/documents/mid-atlantic\%20regional\%20report.pdf.

National Oceanic and Atmospheric Administration (NOAA). 1997b. NOAA's Estuarine Eutrophication Survey. Volume 3: North Atlantic Region. National Oceanic and Atmospheric Administration, National Ocean Service, Office of Ocean Resources Conservation and Assessment. Silver Spring http://www.eutro.org/documents/north\%20atlantic\%20regional\%20 report. pdf.

National Oceanic and Atmospheric Administration (NOAA). 1997c. NOAA's Estuarine Eutrophication Survey. Volume 4: Gulf of Mexico Region. National Oceanic and Atmospheric Administration, National Ocean Service, Office of Ocean Resources Conservation and Assessment. Silver Spring http://www.eutro.org/documents/gulf\%20of\%20mexico\%20regional\%20 report.pdf.

National Oceanic and Atmospheric Administration (NOAA). 1998. NOAA's Estuarine Eutrophication Survey. Volume 5: Pacific Coast Region. National Oceanic and Atmospheric Administration, National Ocean Service, Office of Ocean Resources Conservation and Assessment. Silver Spring http://www.eutro.org/documents/pacific\%20regional\%20report.pdf.

National Research Council (NRC) 2000. Clean Coastal Waters: Understanding and Reducing the Effects of Nutrient Pollution. National Academy Press, Washington. 
Nixon S.W. 1983. Estuarine Ecology: A Comparative and Experimental Analysis using 14 Estuaries and the MERL Ecosystems. Final Report to the U.S. Environmental Protection Agency. Chesapeake Bay Program, Washington.

Ocean Commission. 2004. An Ocean Blueprint for the 21st Century. Final Report. U.S. Commission on Ocean Policy. Washington, DC.

Oslo Paris Convention for the Protection of the North Sea (OSPAR). 2003. OSPAR Integrated Report 2003 on the Eutrophication Status of the OSPAR Maritime Area Based Upon the First Application of the Comprehensive Procedure. OSPAR Commission for the protection of the marine environment of the North-East Atlantic. http://www.eutro.org/documents/p00189_ Eutrophication\%20Status\%20Report\%202003.pdf.

Oslo Paris Convention for the Protection of the North Sea (OSPAR). 2002. Common Assessment Criteria, their Assessment Levels and Area Classification within the Comprehensive Procedure of the Common Procedure. OSPAR Commission for the protection of the marine environment of the North-East Atlantic. http://www.ospar.org/eng/html/welcome.html.

Orth R.J. and Moore K.A. 1984. Distribution and abundance of submerged aquatic vegetation in Chesapeake Bay: An historical perspective. Estuaries 7: 531-540.

Rabalais N.N., Turner R.E., Justic D., Dortch Q., Wiseman W.J. Jr. and Sen Gupta B.K. 1996. Nutrient changes in the Mississippi Rover and system responses on the adjacent continental shelf. Estuaries 19(2B): 386-407.

Rabalais N.N. and Harper Jr. D.E. 1992. Studies of benthic biota in area affected by moderate and severe hypoxia. In: National Oceanic and Atmospheric Administration, Coastal Ocean Program Office, Nutrient Enhanced Coastal Ocean Productivity: Proceedings of a Workshop. Louisiana Universities Marine Consortium, October 1991 (pp. 150-153). Sea Grant Program, Texas A \& M University, Galveston.

Rabalais N.N., Turner R.E., Justić D., Dortch Q. and Wiseman Jr. W.J. 1999. Characterization of Hypoxia: Topic 1 Report for the Integrated Assessment of Hypoxia in the Gulf of Mexico. NOAA Coastal Ocean Program Decision Analysis Series No. 15. National Oceanic and Atmospheric Administration, Coastal Ocean Program, Silver Spring.

Rabalais N.N., Turner R.E. and Scavia D. 2002. Beyond science into policy: Gulf of Mexico Hypoxia and the Mississippi River. BioScience 52: 129-142.

Scavia D., Rabalais N.N., Turner R.E., Justić D. and Wiseman W.J. Jr. 2003. Predicting the response of Gulf of Mexico hypoxia to variations in Mississippi River nitrogen load. Limnol. Oceanogr. 48: 951-956.

Scavia D., Justić D. and Bierman V.J. Jr. 2004. Reducing hypoxia in the Gulf of Mexico: advice from three models. Estuaries 27: 419-425.

Smith C.A. and Maxwell B.A. 2002. Deluxe Integrated System for Clustering Operations (DISCO). http://www.narya.engin.swarthmore.edu/disco/.

Smith S.V., Buddemeier R.W., Bricker S.B., Maxwell B.A., Pacheco P. and Mason A. 2004. Estuarine Typology: Perturbations and eutrophication responses. In: American Society of Limnology and Oceanography and The Oceanography Society 2004 Ocean Research Conference Abstract Book, p. 150. February 15-20, 2004. Hawaii Convention Center, Honolulu. http:// www.aslo.org/honolulu2004/files/aslo-tos-2004-abstracts.pdf.

Smith R.A., Schwarz G.E. and Alexander R.B. 1997. Spatially referenced regressions on watershed attributes (SPARROW). Regional interpretation of water quality monitoring data. Water Resour. Res. 33: 2781-2798.

Stevenson J.C., Staver L.W. and Staver K.W. 1993. Water quality associated with survival of submersed aquatic vegetation along an estuarine gradient. Estuaries 16(2): 346-361.

Task Force. 2001. Mississippi River/Gulf of Mexico Watershed Nutrient Task Force. 2001. Action Plan for Reducing, Mitigating, and Controlling Hypoxia in the Northern Gulf of Mexico. Mississippi River/Gulf of Mexico Watershed Nutrient Task Force, Washington.

Twilley R.R., Kemp W.M., Staver K.W., Stevenson J.C. and Boynton W.R. 1985. Nutrient enrichment of estuarine submersed vascular plant communities. I. Algal growth and effects on production of plants and associated communities. Marine Ecol. Prog. Series 23: 179-191. 
Welsh B. 1991. Anoxia and Hypoxia in Long Island Sound, Chesapeake Bay, and Mobile Bay: A comparative assessment. In: Hinga K.R., Stanley D.W., Klein C.J., Lucid D.T. and Katz M.J. (eds), The National Estuarine Eutrophication Project: Workshop Proceedings. National Oceanic and Atmospheric Administration and the University of Rhode Island Graduate School of Oceanography, Rockville, pp. 35-40 http://www.eutro.org/documents/hinga\%201991.pdf. 